\title{
Paediatric traumatic cardiac arrest: the development of an algorithm to guide recognition, management and decisions to terminate resuscitation
}

\author{
James Vassallo, ${ }^{1,2}$ Tim Nutbeam, ${ }^{1,3}$ Annette C Rickard, ${ }^{1}$ Mark D Lyttle, ${ }^{4,5}$ \\ Barney Scholefield, ${ }^{6}$ Ian K Maconochie, ${ }^{7,8}$ Jason E Smith, ${ }^{1,2}$ on behalf of PERUKI \\ (Paediatric Emergency Research in the UK and Ireland)
}

${ }^{1}$ Emergency Department, Derriford Hospital, Plymouth, UK ${ }^{2}$ Academic Department of Military Emergency Medicine, Royal Centre for Defence Medicine (Research \& Academia), Birmingham, UK ${ }^{3}$ University of Plymouth, Plymouth, UK

${ }^{4}$ Emergency Department, Bristol Royal Children's Hospital, Bristol, UK

${ }^{5}$ Faculty of Health and Applied Sciences, University of West England, Bristol, UK ${ }^{6}$ Birmingham Women's and Children's NHS Foundation Trust, Birmingham, UK

${ }^{7}$ Emergency Department, St Marys Hospital, London, UK

${ }^{8}$ Trauma Audit and Research Network, University of Manchester, Manchester, UK

Correspondence to Dr James Vassallo, Emergency Department, Derriford Hospital, Plymouth, PL6 8DH, UK: vassallo@doctors.org.uk

This work was presented as an oral presentation at the Royal College of Emergency Medicine Annual Scientific Conference in September 2017 by JV.

Received 20 April 2018 Revised 26 July 2018 Accepted 4 August 2018 Published Online First 28 August 2018

\section{Check for updates}

(C) Author(s) (or their employer(s)) 2018. No commercial re-use. See rights and permissions. Published by BMJ.

To cite: Vassallo J Nutbeam T, Rickard AC, et al. Emerg Med J 2018:35:669-674.

\section{ABSTRACT}

Introduction Paediatric traumatic cardiac arrest (TCA)

is a high acuity, low frequency event. Traditionally, survival from TCA has been reported as low, with some believing resuscitation is futile. Within the adult population, there is growing evidence to suggest that with early and aggressive correction of reversible causes, survival from TCA may be comparable with that seen from medical out-of-hospital cardiac arrests. Key to this survival has been the adoption of a standardised approach to resuscitation. The aim of this study was, by a process of consensus, to develop an algorithm for the management of paediatric TCA for adoption in the UK.

Methods A modified consensus development meeting of UK experts involved in the management of paediatric TCA was held. Statements discussed at the meeting were drawn from those that did not reach consensus (positive/ negative) from a linked three-round online Delphi study. 19 statements relating to the diagnosis, management and futility of paediatric TCA were initially discussed in small groups before each participant anonymously recorded their agreement with the statement using 'yes', 'no' or 'don't know'. In keeping with our Delphi study, consensus was set a priori at $70 \%$. Statements reaching consensus were included in the proposed algorithm. Results 41 participants attended the meeting. Of the 19 statements discussed, 13 reached positive consensus and were included in the algorithm. A single statement regarding initial rescue breaths reached negative consensus and was excluded. Consensus was not reached for five statements, including the use of vasopressors and thoracotomy for haemorrhage control in blunt trauma.

Conclusion In attempt to standardise our approach to the management of paediatric TCA and to improve outcomes, we present the first consensus-based algorithm specific to the paediatric population. While this algorithm was developed for adoption in the UK, it may be applicable to similar healthcare systems internationally.

\section{INTRODUCTION}

Paediatric traumatic cardiac arrest (TCA) is a high acuity, low frequency event. Less than 15 cases are reported per year in the UK. ${ }^{1}$ Traditionally, survival has been reported as low, with some studies suggesting that resuscitation of children in TCA is futile with universally poor outcomes. ${ }^{2}$ However,

\section{Key messages}

What is already known on this subject

- Paediatric traumatic cardiac arrest is a high acuity, low frequency event.

- Key to the improvement in survival observed in the adult population has been the adoption of an aggressive and standardised approach to resuscitation in victims of traumatic cardiac arrest.

- There is currently a lack of consensus as to the optimum management of the paediatric patient in traumatic cardiac arrest, with no standardised approach available.

\section{What this study adds}

- Based on a previously reported Delphi study, this paper provides the first consensus-based algorithm for the management of paediatric traumatic cardiac arrest.

- By providing this algorithm, we believe that a standardised and aggressive approach can be undertaken in major trauma centres and in trauma units.

there is growing evidence that with early and aggressive correction of potentially reversible causes in the adult population, survival rates from TCA are comparable with that seen with medical out-of-hospital cardiac arrests. ${ }^{34}$ Key to this survival has been the adoption of a standardised approach to TCA management and the development of specific TCA algorithms. ${ }^{4}$ These are now taught as part of trauma life support courses including the European Trauma Course and are endorsed by the European Resuscitation Council. ${ }^{5}$ Currently, there is no specific or standardised approach to paediatric TCA, but both the APLS and European Paediatric Advanced Life Support courses advocate the standard basic life support approach, along with the correction of identified reversible causes and the regular administration of epinephrine. ${ }^{67}$

In 2013, both Lockey and Sherren published guidelines for the management of TCA in adults within their respective organisations (London's Air Ambulance and Sydney HEMS), describing the evidence-based rationale for the approaches contained within. ${ }^{8}{ }^{9}$ Subsequently in 2015 and 
Box 1 Statements agreed following Delphi consensus ${ }^{10}$

\section{Concept/definition of paediatric traumatic cardiac arrest \\ (TCA)}

- Blunt and penetrating trauma should be treated differently.

- Absent palpable pulses or no signs of life should trigger a paediatric TCA algorithm.

- The absence of cardiac activity on ultrasound should trigger a paediatric TCA algorithm.

Process

- Whole blood therapy improves survival.

- Warmed blood/fluids improves survival.

- Rapid volume replacement improves survival.

- Thoracotomy in penetrating trauma improves survival.

- Pericardiocentesis should not be performed in paediatric TCA.

- Ensuring oxygenation (via an endotracheal tube or supraglottic device) improves survival.

- Providing ventilatory support improves survival.

Decision to stop

- Duration of arrest in paediatric TCA is helpful in determining the futility of continued resuscitation.

- The lack of response to any intervention is helpful in determining the futility of continued resuscitation.

- If all invasive procedures have been completed and there is no return of spontaneous circulation, this is helpful in determining the futility of continued resuscitation.

- Cardiac standstill on ultrasound is helpful in determining the futility of continued resuscitation, in the presence of appropriate resources and a trained operator.

2017, both the European and UK Resuscitation Councils published TCA treatment algorithms for adults to inform clinical priorities and intervention. ${ }^{5}$ However, there is currently no accepted national or international guidance specific to children in TCA. With a paucity of evidence surrounding the management of paediatric TCA and with the majority of clinicians only having limited experience, we undertook a programme of work to derive expert consensus opinion to define the optimum management of paediatric TCA and construct an algorithm to guide clinical practice.

We have previously reported a three-round Delphi process with an expert panel of 73 participants that achieved consensus on 14 statements relating to the recognition, management and cessation of paediatric TCA (box 1). ${ }^{10}$

In this element of the development package, we aimed to: (1) explore the statements not reaching consensus during the online Delphi phase and (2) incorporate the consensus from both phases to develop a national standardised TCA algorithm for the paediatric patient (defined as a patient aged $0-16$ years in keeping with previous studies).

\section{METHODS}

A modified consensus development conference was held in Birmingham, UK, on 8 March 2017. Those who were invited to take part in the first round of the Delphi process $(n=133)$ were invited to attend the meeting, and additional invitations were circulated via the Royal College of Emergency Medicine, Paediatric Emergency Research in the UK and Ireland (PERUKI) and the Faculty of Prehospital Emergency Care. PERUKI is a collaborative network of clinicians from 63 sites across the UK and Ireland (including all paediatric major trauma centres), which has a focus on improving paediatric emergency care through evidence. $^{11}$

As an open forum, participants $(n=41)$ were not blinded to one another. The initial part of the conference involved the presentation of existing evidence in the form of topic-specific systematic reviews.

The second part of the meeting was dedicated to exploring statements that did not reach consensus during the Delphi process. ${ }^{10}$ Nineteen questions relating to the definition, diagnosis management and termination of resuscitation of paediatric TCA were given to the participants to discuss in small groups of between five and seven participants. After 5 minutes, key points from the discussions were presented from each small group to all participants.

Subsequently, each individual participant was asked to vote on their agreement with the statement in question using electronic voting devices, by voting 'yes', 'no' or 'don't know'. Participants were not blinded to one another, but the use of the individual electronic voting devices allowed for anonymous voting. The study team facilitated the discussions and presented the questions but did not take part in the voting process.

Consensus was set a priori at $70 \%$ of the total number of participants responding to each statement. This process was repeated for each statement with a single round of voting conducted for each statement. For standardisation of responses, those not recording a vote for a statement were included in the 'don't know' category. Results were collated using a Microsoft Excel spreadsheet. An algorithm was then constructed using statements reaching positive or negative consensus and based on adult TCA algorithms previously published. Statements that failed to reach consensus have not been included in the algorithm.

In keeping with previous work, TCA was defined as cardiac arrest following a primary traumatic mechanism of injury, that is, as a result of energy transfer or traumatic body cavity penetration. Patients in cardiac arrest following mechanisms associated with asphyxia or suffocation, drowning and electrocution were not included in this definition as their management differs from that of TCA. ${ }^{1410}$

\begin{tabular}{lc}
\hline Table 1 & Background characteristics of participants \\
\hline \multicolumn{2}{c}{ Number (\%) } \\
\hline Specialty & $4(9.8)$ \\
\hline Anaesthetics & $2(4.9)$ \\
Anaesthetics/prehospital care & $2(4.9)$ \\
Anaesthetics/paediatric intensive care & $4(9.8)$ \\
Emergency medicine & $3(7.3)$ \\
Emergency medicine/paediatric emergency medicine & $2(4.9)$ \\
Emergency medicine/prehospital care & $4(9.8)$ \\
Military & $14(34.1)$ \\
Paediatric emergency medicine & $3(7.3)$ \\
Prehospital care & $2(4.9)$ \\
Paediatric intensive care & $1(2.4)$ \\
Resuscitation officer & \\
Grade & $28(68.2)$ \\
Consultant & $5(12.2)$ \\
Higher trainee (PGY6+) & $8(19.5)$ \\
\hline Other &
\end{tabular}

*Military medics, paramedics and resuscitation officer. PGY, postgraduate year. 
Table 2 Results of the consensus development meeting

\begin{tabular}{|c|c|c|c|c|c|c|}
\hline & Statements & $\begin{array}{l}\text { Responses, } \\
\mathrm{n}\end{array}$ & $\begin{array}{l}\text { Agree, } \\
\mathrm{n}(\%)\end{array}$ & $\begin{array}{l}\text { Disagree, } \\
\mathrm{n}(\%)\end{array}$ & $\begin{array}{l}\text { Don't know, } \\
\mathrm{n}(\%)\end{array}$ & Outcome \\
\hline 1 & Paediatric TCA should be treated in the same way across the entire age range. & 39 & $31(79.5)$ & $7(17.9)$ & $1(2.6)$ & Positive \\
\hline 2 & In paediatric TCA, rescue breaths should be given at the entry to the algorithm. & 40 & $12(30.0)$ & $28(70.0)$ & 0 & Negative \\
\hline 4 & Do vasopressors have a role in the management of paediatric TCA secondary to isolated TBI? & 39 & $28(71.8)$ & $4(10.3)$ & $7(17.9)$ & Positive \\
\hline 5 & $\begin{array}{l}\text { Management of paediatric TCA should be the same regardless of presenting cardiac rhythm } \\
\text { (shockable/non-shockable). }\end{array}$ & 39 & $28(71.8)$ & $8(20.5)$ & $3(7.7)$ & Positive \\
\hline 7 & Use of vasopressors (including epinephrine) at any time in paediatric TCA. & 40 & $13(32.5)$ & $11(27.5)$ & $16(40.0)$ & N/A \\
\hline 8 & $\begin{array}{l}\text { In blunt trauma, closed chest compressions should be performed when hypoxia is the likely } \\
\text { cause of paediatric TCA. }\end{array}$ & 40 & $37(92.5)$ & 0 & $3(7.5)$ & Positive \\
\hline 9 & $\begin{array}{l}\text { In paediatric TCA secondary to blunt trauma, chest compressions should be deprioritised in } \\
\text { favour of performing other life-saving interventions. }\end{array}$ & 40 & $40(100)$ & 0 & 0 & Positive \\
\hline 10 & $\begin{array}{l}\text { In paediatric TCA secondary to penetrating trauma, chest compressions should be deprioritised } \\
\text { in favour of performing other life-saving interventions. }\end{array}$ & 40 & $40(100)$ & 0 & 0 & Positive \\
\hline 13 & In paediatric TCA consider performing bilateral thoracostomies. & 40 & $38(95.0)$ & $1(2.5)$ & $1(2.5)$ & Positive \\
\hline 14 & In paediatric TCA secondary to blunt trauma consider the application of a pelvic binder. & 40 & $39(97.5)$ & $1(2.5)$ & 0 & Positive \\
\hline 15 & $\begin{array}{l}\text { In paediatric TCA secondary to blunt injury, thoracotomy for haemorrhage control should be } \\
\text { considered. }\end{array}$ & 40 & $14(35.0)$ & $16(40.0)$ & $10(25.0)$ & N/A \\
\hline 16 & Having achieved ROSC following paediatric TCA consider the use of vasopressors presurgery. & 40 & $16(40.0)$ & $9(22.5)$ & $15(37.5)$ & $\mathrm{N} / \mathrm{A}$ \\
\hline 17 & $\begin{array}{l}\text { Having achieved ROSC following paediatric TCA secondary to TBI, consider the use of } \\
\text { vasopressors. }\end{array}$ & 41 & $31(75.6)$ & 0 & $10(24.4)$ & Positive \\
\hline 18 & Consider the use of $\mathrm{ETCO}_{2}$ to guide the futility of continued resuscitation efforts. & 41 & $33(80.5)$ & $3(7.3)$ & $5(12.2)$ & Positive \\
\hline 19 & $\begin{array}{l}\text { Having achieved ROSC following paediatric TCA consider the use of vasopressors in those } \\
\text { without TBI. }\end{array}$ & 40 & $9(22.5)$ & 15 (37.5) & $16(40.0)$ & N/A \\
\hline
\end{tabular}

$\mathrm{ETCO}_{2}$, end tidal carbon dioxide; ROSC, return of spontaneous circulation; TBI, traumatic brain injury; TCA, traumatic cardiac arrest.

\section{RESULTS}

In total, 41 individuals from a variety of backgrounds attended the consensus development meeting (table 1). The overwhelming majority of participants were consultants, mostly from paediatric emergency medicine. Responses to questions are shown in table 2, along with the number of participants responding for each statement.

Of the 19 statements, 13 reached positive consensus and were included in the paediatric TCA algorithm (figure 1). The statement 'in paediatric TCA, rescue breaths should be given at entry to the algorithm' reached negative consensus and was therefore not included in the algorithm. Consensus was not reached for five statements.

\section{Discussion and rationale for algorithm}

This process has for the first time enabled the production of an algorithm (figure 1) to guide the management of TCA in the paediatric population and to provide a basis for the evaluation of outcomes and for identifying areas of further research into developing effective systems for the provision of optimal care. The algorithm provided in figure 1 bears similarity to existing published algorithms for the adult population, focusing on the rapid management of potentially reversible causes. ${ }^{7-9} 12$

Resuscitation algorithms are commonly used in emergency medicine, with clinicians trained in their use for the medical management of cardiac arrest in both adults and children. In high acuity, low frequency situations such as paediatric TCA, the provision of an algorithm ensures a standardised and structured approach, which can mitigate inevitable human factors stressors.
This could be even more relevant in hospitals that are not designated major trauma centres (equivalent to level 1 trauma centres), where resuscitation is being coordinated by a team less familiar with managing severe trauma in children. Despite the regionalisation of trauma services, $50 \%-60 \%$ of severely injured children present initially to hospitals not designated as major trauma centres, as a result of either self-presentation, geographical location or the severity of their injuries. ${ }^{13}$

During the development meeting, it was agreed that paediatric TCA should be treated with the same principles across the paediatric age range (0-16 years). The definition of TCA is a patient sustaining trauma with no palpable central pulse and either agonal or absent spontaneous respirations. ${ }^{5}$ In clinical practice, it was agreed that the absence of signs of life, no palpable pulses or a lack of cardiac activity on ultrasound should prompt entry into the paediatric TCA algorithm. The lack of cardiac activity on ultrasound assumes that an appropriately trained and qualified operator is available to perform the procedure. ${ }^{9}$

\section{Simultaneous life-saving interventions}

In keeping with the 2016 updated APLS guidelines, control of external haemorrhage is included in initial life-saving interventions. ${ }^{6}$ Over the last decade, terrorist incidents in Western Europe have increased, bringing a pattern of injuries that have traditionally only been seen on the battlefield, including traumatic limb amputations and blast injuries. ${ }^{14}$ While not specific to the paediatric population, the indiscriminate nature of these attacks frequently results in children being affected. ${ }^{15}$ When applicable (such as following a traumatic amputation secondary 

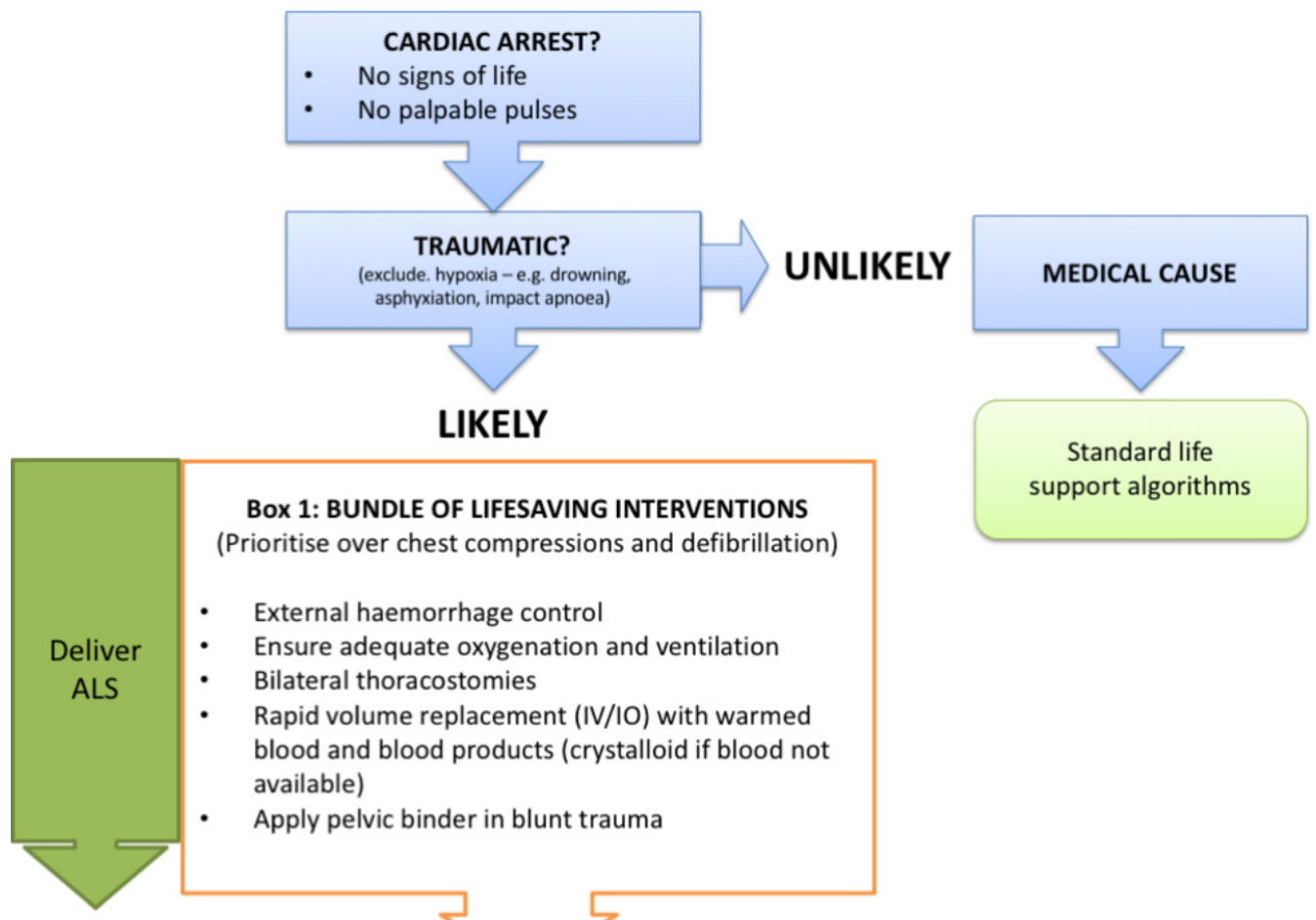

Box 1: BUNDLE OF LIFESAVING INTERVENTIONS

(Prioritise over chest compressions and defibrillation)

- External haemorrhage control

- Ensure adequate oxygenation and ventilation

- Bilateral thoracostomies

- Rapid volume replacement (IV/IO) with warmed blood and blood products (crystalloid if blood not available)

- Apply pelvic binder in blunt trauma
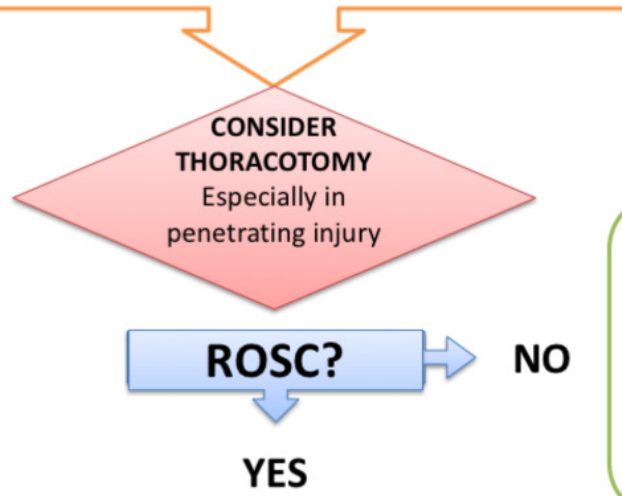

Decision to STOP resuscitation can be guided by -

- Duration of cardiac arrest

- Lack of response to lifesaving interventions (Box 1)

- Persistently low $\mathrm{ETCO}_{2}$

- Cardiac standstill on US

Figure 1 Paediatric TCA algorithm. ETCO $2^{\prime}$ end tidal carbon dioxide; PICU, paediatric intensive care unit; ROSC, return of spontaneous circulation; TCA, traumatic cardiac arrest.

to a blast injury), the control of external haemorrhage using tourniquets and haemostatic dressings is a simple intervention associated with increased survival. ${ }^{16} 17$

In keeping with adult TCA algorithms, consensus was reached regarding the initial management of paediatric TCA, with the rapid identification and simultaneous correction of hypoxia, hypovolaemia, tension pneumothorax and cardiac tamponade. ${ }^{8918}$ This has been represented in the algorithm in box 1, which describes a bundle of potentially life-saving interventions that should be undertaken simultaneously by the resuscitating team. The intention is to provide one algorithm to guide management in all circumstances, but there may be occasions where not all of these interventions are appropriate, if a reversible cause can be excluded or if the situation is judged to be futile, guided by senior clinical decision makers. In the presence of a multidisciplinary trauma team, the interventions can be undertaken simultaneously, but this may be limited by the number and skills of the team.

Effective oxygenation and ventilation is a key principle of trauma resuscitation, and correcting hypoxia is essential in the reversal of hypoxic cardiac arrest. ${ }^{5}$ During the Delphi process, consensus was reached that the correction of hypoxia should be optimised where possible by using an endotracheal tube or supraglottic device placed by an appropriately skilled individual in either the prehospital or hospital environment.

Performing bilateral finger thoracostomies is recommended in adult TCA and has replaced needle thoracocentesis in the initial management of tension pneumothorax in the context of TCA. $^{89}$ This topic was reviewed during the consensus development meeting, where it was strongly supported (95.0\%) that bilateral thoracostomies should be performed instead of needle thoracocentesis in paediatric TCA. ${ }^{19}$ However, we acknowledge 
that needle thoracocentesis continues to be taught as the primary method of chest decompression on paediatric life support courses, and individuals may therefore elect to perform needle thoracocentesis ahead of thoracostomy. ${ }^{7}$

With severe haemorrhage implicated in the majority of reversible cases of paediatric TCA, the rapid identification and reversal of hypovolaemia is vital in the attempt to improve survival. ${ }^{1}$ Epidemiological studies in both the adult and paediatric population demonstrate that, within the UK, the majority of severe haemorrhage is within the thoracic cavity and is therefore non-compressible. ${ }^{14}$ Consensus was reached during the Delphi study that hypovolaemia should be corrected by the rapid restoration of blood volume using warmed whole blood. When blood is not immediately available, the temporary use of warmed crystalloid infusions was advised. As with the management of the critically unwell medical paediatric patient, early circulatory access, either via the intravenous or intraosseous route, is essential in the management of paediatric TCA..$^{20}$

In the context of blunt trauma, the application of an appropriately sized pelvic binder (if not already done in the prehospital setting) is part of the management of non-compressible haemorrhage and reversal of hypovolaemia for lower girdle injuries. ${ }^{22}$

Cardiac tamponade following penetrating trauma is well described in the adult population, and survival following thoracotomy (within 10 min of cardiac arrest) in this group of patients is as high as $18 \%{ }^{23}$ In keeping with adult recommendations, the Delphi group reached consensus favouring thoracotomy for penetrating trauma to relieve possible cardiac tamponade. There was discussion about the role of thoracotomy in blunt trauma, as it can be used to relieve tamponade, contain pulmonary bleeding and to apply aortic compression for proximal control of haemorrhage below the diaphragm. ${ }^{24}{ }^{25}$ However, the group failed to reach consensus for or against thoracotomy in blunt paediatric TCA, and it is therefore presented as an option for consideration, but without clear recommendation, within the algorithm. This remains a key area for future trauma registry work.

While cardiac chest compressions are recommended as the mainstay of basic life support for both adult and paediatric patients in medical cardiac arrest, ${ }^{26-28}$ in the TCA setting, cardiac chest compressions have been deprioritised in adults until potential reversible causes have been addressed. ${ }^{5}$ The consensus meeting achieved unanimous $100 \%$ agreement in the deprioritisation of chest compressions in both penetrating and blunt paediatric TCA. However, the group achieved consensus in supporting the delivery of chest compressions once interventions to address the main potentially reversible causes (hypoxia, tension pneumothorax, hypovolaemia and cardiac tamponade) have been achieved.

The use of vasopressors in the context of trauma to allow catch-up with blood products is an area of controversy in adult trauma practice, with currently little or no evidence for their use and one study demonstrating potential harm from their administration..$^{29}{ }^{30}$ The group failed to reach positive or negative consensus on the use of vasopressors (either by bolus or infusion) before return of spontaneous circulation (ROSC) in the context of any paediatric TCA (including paediatric TCA from suspected isolated traumatic brain injury (TBI)). We acknowledge that there may be a small cohort of paediatric patients in TCA where the use of vasopressors will be required, particularly in the context of neurogenic shock combined with hypovolaemia. After ROSC from paediatric TCA, the group failed to achieve consensus regarding the use of vasopressors except in the context of those patients with isolated TBI, in which case a blood pressure should be maintained at a level sufficient to provide neuroprotection but balancing this against the risk of destabilising other injuries (including clot formation).

The group supported the deprioritisation of defibrillation of a shockable rhythm in the setting of paediatric TCA while other reversible causes were addressed (see suggested algorithm). Once reversible causes have been addressed, the group supported defibrillation in such circumstances where a shockable rhythm is present.

The cessation of resuscitation attempts in children in TCA is challenging, and recognition of features suggesting futility is important in supporting such a decision. In adult medical cardiac arrest, end tidal carbon dioxide $\left(\mathrm{ETCO}_{2}\right)$ has been used to determine the futility of continued resuscitation. ${ }^{3132}$ While we are unaware of similar studies in either the paediatric population or TCA cohort, the group agreed that the use of $\mathrm{ETCO}_{2}$ may be useful in determining the futility of ongoing resuscitation. Reaching the end of the suggested algorithm without ROSC was also discussed as a marker of futility and a point at which further resuscitation efforts may be withdrawn.

The main limitation for this study is that the algorithm was by necessity based on consensus rather than robust clinical evidence. The lack of evidence suggests that future research is needed to answer some of these research questions. In the meantime, it is hoped that reaching consensus on at least some aspects of the recognition and management of patients in TCA will provide a useful framework on which clinicians might base their management.

\section{CONCLUSION}

Within the UK, paediatric TCA is a high acuity, low frequency event. In attempt to standardise our approach to its management and to improve outcomes, we present the first consensus-based algorithm specific to the paediatric trauma population. This may be applicable to similar healthcare systems internationally.

\section{Twitter @jamievassallo}

Acknowledgements We would like to thank the following for attending the Consensus Development Day: Roger Alcock, Dawn Ball, Mark Beasley, Sophie Butterworth, Sam Cooper, Phil Cowburn, Darren Darby, Kerry Davis, Peter Davis, Alice Downes, Naomi Edmonds, Laura Fallon, Andrew Fitzsimmons, Kunal Gadhvi, Chris Gough, Stuart Hartshorn, Giles Haythornthwaite, Ali Husain, Andras Husz, Hayley Jarman, Graham Johnson, Damian Keene, Suzie Kellett, Miki Lazner, Liz Ledger, Caroline Leech, Danielle Leemon, Gareth Lewis, Julie-Ann Maney, Jon McCormack, Kat Moore, Dan Nevin, Breda O'Neill, Clare O'Connell, Rebecca Powell, Sarah Prudhoe, Gisela Robinson, Elizabeth Saunders, Barney Scholefield, Karl Thies, Tom Waterfield and Bridget Wilson.

Contributors The authors JV, TN, ACR, MDL and JES conceived, designed and conducted the study and were responsible for the acquisition of data. JV and TN analysed and interpreted the data and drafted the first manuscript. All remaining authors, ACR, MDL, JES, BS and IKM were responsible for revising it critically for important intellectual content. JV conducted the revisions to the manuscript, with MDL and JES critically reviewing it for important intellectual content. All authors reviewed the final second manuscript prior to resubmission. JV takes responsibility for the manuscript as guarantor.

Funding The authors have not declared a specific grant for this research from any funding agency in the public, commercial or not-for-profit sectors.

Competing interests Two of the authors (JV and JES) are serving members of the UK Royal Navy.

Patient consent Not required.

Provenance and peer review Not commissioned; externally peer reviewed.

\section{REFERENCES}

1 Vassallo J, Webster M, Barnard E, et al. 54 Paediatric traumatic cardiac arrest in England and Wales a 10 year epidemiological study. Emerg Med J 2017;34:A897-9.

2 Deasy C, Bray J, Smith K, et al. Paediatric traumatic out-of-hospital cardiac arrests in Melbourne, Australia. Resuscitation 2012;83:471-5

3 Perkins GD, Lockey AS, de Belder MA, et al. National initiatives to improve outcomes from out-of-hospital cardiac arrest in England. Emerg Med J 2016;33:448-51. 
4 Barnard E, Yates D, Edwards A, et al. Epidemiology and aetiology of traumatic cardiac arrest in England and Wales - A retrospective database analysis. Resuscitation 2017;110:90-4.

5 Truhlár A, Deakin CD, Soar J, et al. European resuscitation council guidelines for resuscitation 2015: section 4. Cardiac arrest in special circumstances. Resuscitation 2015:95:148-201.

6 Advanced Life Support Group. Advanced Paediatric Life Support a practical approach to emergencies. 6th edn. West Sussex: Wiley, 2016.

7 Phillips BM, Mackway-Jones K, Jewkes F. The European Resuscitation Council's paediatric life support course 'Advanced Paediatric Life Support'. Resuscitation 2000;47:329-34.

8 Lockey DJ, Lyon RM, Davies GE. Development of a simple algorithm to guide the effective management of traumatic cardiac arrest. Resuscitation 2013;84:738-42.

9 Sherren PB, Reid C, Habig K, et al. Algorithm for the resuscitation of traumatic cardiac arrest patients in a physician-staffed helicopter emergency medical service. Crit Care 20049;17(Suppl 2):P281.

10 Rickard AC, Vassallo J, Nutbeam T, et al. Paediatric traumatic cardiac arrest: a Delphi study to establish consensus on definition and management. Emerg Med J 2018;35:434-9.

11 Lyttle MD, O'Sullivan R, Hartshorn S, et al. Pediatric emergency research in the UK and Ireland (PERUKI): developing a collaborative for multicentre research. Arch Dis Child 2014;99:602-3.

12 McEvoy MD, Thies KC, Einav $S$, et al. Cardiac arrest in the operating room: part 2-special situations in the perioperative period. Anesth Analg 2018;126:889-903.

13 Davies FC, Lecky FE, Fisher $\mathrm{R}$, et al. Major trauma from suspected child abuse: a profile of the patient pathway. Emerg Med J 2017;34:562-7.

14 Hirsch M, Carli P, Nizard R, et al. The medical response to multisite terrorist attacks in Paris. Lancet 2015;386:2535-8.

15 Craigie RJ, Farrelly PJ, Santos R, et al. Manchester Arena bombing: lessons learnt from a mass casualty incident. J R Army Med Corps 2018:jramc-2018-000930 (Epub ahead of print 6 Apr 2018).

16 Drew B, Bennett BL, Littlejohn L. Application of current hemorrhage control techniques for backcountry care: part one, tourniquets and hemorrhage control adjuncts. Wilderness Environ Med 2015;26:236-45.

17 Bulger EM, Snyder D, Schoelles K, et al. An evidence-based prehospital guideline for external hemorrhage control: American College of Surgeons Committee on Trauma. Prehosp Emerg Care 2014;18:163-73.
18 Resuscitation Council (UK). Traumatic cardiac arrest treatment algorithm 2015. 2018 https://www.resus.org.uk/EasySiteWeb/GatewayLink.aspx?alld=6464 (accessed 16 Mar 2018)

19 Seamon MJ, Haut ER, Van Arendonk K, et al. An evidence-based approach to patient selection for emergency department thoracotomy. J Trauma Acute Care Surg 2015;79:159-73.

20 Haas NA. Clinical review: vascular access for fluid infusion in children. Crit Care 2004;8:478-84.

21 de Caen A. Venous access in the critically ill child: when the peripheral intravenous fails!. Pediatr Emerg Care 2007;23:422-4.

22 Jakob H, Lustenberger T, Schneidmüller D, et al. Pediatric polytrauma management. Eur J Trauma Emerg Surg 2010;36:325-38.

23 Davies GE, Lockey DJ. Thirteen survivors of prehospital thoracotomy for penetrating trauma: a prehospital physician-performed resuscitation procedure that can yield good results. J Trauma 2011;70:E75-8.

24 Mejia JC, Stewart RM, Cohn SM. Emergency department thoracotomy. Semin Thorac Cardiovasc Surg 2008;20:13-18.

25 Hunt PA, Greaves I, Owens WA. Emergency thoracotomy in thoracic trauma-a review. Injury 2006;37:1-19.

26 Kitamura T, Iwami T, Kawamura T, et al. Conventional and chest-compression-only cardiopulmonary resuscitation by bystanders for children who have out-of-hospital cardiac arrests: a prospective, nationwide, population-based cohort study. Lancet 2010;375:1347-54.

27 Bobrow BJ, Spaite DW, Berg RA, et al. Chest compression-only CPR by lay rescuers and survival from out-of-hospital cardiac arrest. JAMA 2010;304:1447-54.

28 Svensson L, Bohm K, Castrèn M, et al. Compression-only CPR or standard CPR in outof-hospital cardiac arrest. N Engl J Med 2010;363:434-42.

29 Smith JE, Rickard A, Wise D. Traumatic cardiac arrest. J R Soc Med 2015;108:11-16.

30 Sperry JL, Minei JP, Frankel HL, et al. Early use of vasopressors after injury: caution before constriction. J Trauma 2008;64:9-14.

31 Levine RL, Wayne MA, Miller CC. End-tidal carbon dioxide and outcome of out-ofhospital cardiac arrest. N Engl J Med 1997;337:301-6.

32 Kolar M, Krizmaric M, Klemen P, et al. Partial pressure of end-tidal carbon dioxide successful predicts cardiopulmonary resuscitation in the field: a prospective observational study. Crit Care 2008;12:R115. 